\title{
Antibacterial and antioxidant effects of Thymus daenensis essential oil
}

\section{Seyed Heibatollah Hosseini ${ }^{*}$}

${ }^{1}$ MSc Medicinal Plants, Faculty of Agriculture and Food Industry, Islamic Azad University, Shahrekord Branch, Shahrekord, Iran

\begin{abstract}
Thymusdaenensis is an Iranian medicinal plant with high antibacterial and antioxidant effects. The present study was done to investigate the antibacterial and antioxidant effects of $T$. daenensis essential oil collected from the Dena mountain, Iran. T. daenensis was collected and immediately transferred to the laboratory. After its approval by an expert person, its essential oil was extracted using the Clevenger apparatus. DPPH free radical scavenging activity and antibacterial effects of various concentration of $T$. daenensis essential oil were studied. Higher concentrations of the $T$. daenensis essential oil had higher antibacterial and antioxidant effects. $T$. daenensis essential oil in a concentration of $1 \mathrm{mg} / \mathrm{ml}$ had the highest inhibitory effects on the DPPH radicals $(96.27 \pm 8.60 \%)$. The mean dimeter of the zone of inhibition for tested bacteria had a range of $6.03 \pm 0.28$ to $19.29 \pm 1.57$ millimeter. The highest antibacterial effects were seen for the $1 \mathrm{mg} / \mathrm{ml}$ concentration of $T$. daenensis essential oil on all tested bacteria and especially on E. coli $(19.29 \pm 1.57 \mathrm{~mm})$ and $K$. pneumonia $(18.0 \pm 1.69 \mathrm{~mm})$. Bacteria were resistant against some of tested antibiotic agents and especially tetracycline, gentamicin and penicillin G. Essential oil of T. daenensis had a higher antibacterial effects on its high concentrations than several types of antibiotic agents. We found that T. daenensis essential oil is a good source for production of natural antioxidant and antibacterial agents.
\end{abstract}

KEY WORDS: ANTIBACTERIAL, PATHOGENIC BACTERIA, ANTIOXIDANT, DPPH RADICALS, THYMUS DAENENSIS, ESSENTIAL OIL

\section{INTRODUCTION}

Pathogenic agents and especially bacteria are the most important causes of infections in hospitals. Staphylococcus aureus (S. aureus), Escherichia coli (E. coli), Liste- ria monocytogenes (L. monocytogenes), Bacillus cereus (B. cereus), Pseudomonas aeruginosa (P. aeruginosa) and Klebsiella pneumoniae (K. pneumoniae) are the most important causes of gastrointestinal, respiratory, burn, wound, soft-tissue, and urinary tract infections

\section{ARTICLE INFORMATION:}

*Corresponding Author: Heybat_s@yahoo.com. Received $18^{\text {th }} \mathrm{Feb}, 2017$

Accepted after revision $29^{\text {th }}$ May, 2017

BBRC Print ISSN: 0974-6455

Online ISSN: 2321-4007 CODEN: USA BBRCBA

. Thomson Reuters ISI ESC and Crossref Indexed Journal

NAAS Journal Score 2017: 4.31 Cosmos IF : 4.006

- A Society of Science and Nature Publication, 2017. All rights reserved.

Online Contents Available at: http//www.bbrc.in/ 
al-around the world.They are also important causes of food-borne diseases globally (Ruhnke-Trautmann et al. 1989; Woodford and Livermore, 2009 andKaye and Pogue, 2015).

Bacterial strains of clinical infections harbored the high levels of resistance against the extensive ranges of antibiotics including beta-lactams, macrolides, tetracyclines, cephalosporins, sulfonamides and aminoglycosidesantibiotics (Zhang et al., 2006; Huttner et al. 2013). Therefore, much attentions have been done to the prescription of medicinal plants for treatment of various types of infectious diseases (Zhang et al., 2006; Huttner et al. 2013). The genus Thymus, member of the Lamiaceae family, contains about 400 species of perennial aromatic, evergreen or semi-evergreen herbaceous plants with many subspecies, varieties, subvarieties and forms (Vardar-Unlü et al. 2003; Ulukanli et al. 2011; Jia et al. 2010; Zarshenas and Krenn, et al. 2015).

They are known as "Avishan" in Persian and are well-known aromatic perennial herbs originated from Mediterranean region. Among 215 species of this genus grown in the world, 14 species are distributed in Iranian flora (Vardar-Unlü et al. 2003; Ulukanli et al. 2011; Jia et al. 2010; Zarshenas and Krenn, et al. 2015). Thymus species are well known as medicinal plants because of their biological and pharmacological properties. In traditionalmedicine, leaves and flowering parts of Thymus species are widely used as tonic and herbal tea, antiseptic, antitussive, antibacterial, antifungal, antioxidant and carminative as well as treating colds (Vardar-Unlü et al. 2003; Ulukanli et al. 2011; Jia et al. 2010; Zarshenasand Krenn, et al. 2015).

Thymus oils and extracts are widely used in pharmaceutical, cosmetic, and perfume industry, also for flavoring and preservation of several food products (VardarUnlü et al. 2003; Ulukanli et al. 2011; Jia et al. 2010; Zarshenas and Krenn, et al. 2015). Thymus daenensis (T.daenensis) is one of those endemic species in Iran and is widely used as medicine and food additive. It a source of antibacterial and antioxidant components (VardarUnlü et al. 2003; Ulukanli et al. 2011; Jia et al. 2010; Zarshenas and Krenn, et al. 2015). Data on the antibacterial and antioxidant effects of T.daenensis are scarce in the world. Therefore, the present study was done to investigate the antioxidant effects of the $T$. daenensis essential oil as well as its antibacterial effects on several types of pathogenic bacteria.

\section{MATERIALS AND METHODS}

From May to August 2016, aerial parts of T. daenensis at the flowering stage were collected from the Dena mountain slopes, Yasuj, Iran. Plants were identified by an expert person in the field of medicinal plants at theHerbarium of Research Center of Agricultural of Shahrekord city, Iran. T. daenensis samples were dried at ambient conditions for 10 days. The dried plant was used to extract the essential oil. Essential oil of the collected $T$. daenensis was extracted by water distillation using the Clevenger apparatus. $T$. daenensis essential oil was prepared at a concentration of 0.25, 0.5, 0.75 and $1 \mathrm{mg} / \mathrm{ml}$. Radical-scavenging activities of $T$. daenensis essential oilwas determined against 2,2-diphenyl-1-picrylhydrazyl (DPPH) free radicals. Briefly, $3 \mathrm{~mL}$ of $T$. daenensis essential oil was mixed with $1 \mathrm{~mL}$ of $1 \mathrm{mMmethanolic}$ solution of DPPH (Merck, Darmstadt, Germany). The mixture was vortexed and incubated in the dark at ambient temperature for $30 \mathrm{~min}$. When the DPPH solution was mixed with the sample mixture acting as a hydrogen atom donor, a stable non radical form of DPPH is obtained with simultaneous change of the violet color to pale yellow. The absorbance was then measured at $517 \mathrm{~nm}$. The percentage of DPPH free radical quenching activity was determined using the following equation:

Percent of the DPPH scavenging effect $=\frac{\text { Abs of DPPH-Abs of extract }}{\text { Abs of DPPH }} \times 100$

Where Abs DPPH is the absorbance value at $517 \mathrm{~nm}$ of the methanolic solution of DPPH and Abs extract is the absorbance value at $517 \mathrm{~nm}$ for the sample extracts. DPPH radical scavenging of $T$. daenensis essential oilwas also compared with the BHT synthetic antioxidant.

Simple disk diffusion method was used to study the diameter of zone of inhibition of several types of bacteria subjected to T. daenensis essential oil. Susceptibility of Staphylococcus aureus (S. aureus) ATCC 25923, Escherichia coli (E. coli) ATCC 25922, Listeria monocytogenes (L. monocytogenes) ATCC 19111, Bacillus cereus (B. cereus) ATCC 14579, Pseudomonas aeruginosa (P. aeruginosa) ATCC 27853 and Klebsiella pneumoniae (K. pneumonie) ATCC 43816 (Pasteur Institute, Iran) were determined against the $T$. daenensis essential oil. Guidelines of the Clinical and Laboratory Standard Institute (CLSI) were used to study the antibacterial effects of $T$. daenensis essential oil. Susceptibility of bacterial strains were also studied against tetracycline (30 $\mu \mathrm{g} /$ disk), azithromycin (15 $\mu \mathrm{g} /$ disk), gentamicin (10 $\mu \mathrm{g} /$ disk $)$, penicillin $\mathrm{G}$ (10 u/disk), and ciprofloxacin ( $5 \mathrm{\mu g} /$ disk) antibiotic disks (Oxoid, UK). Base plates were prepared by pouring Muller-Hinton (MH) agar into sterile Petri dishes and allowed to set. Plant essential oil aliquots of $10 \mu \mathrm{l}$ were applied per filter paper disc (Whatman No $6 \mathrm{~mm}$ diameter). The disc was air-dried and placed onto the seeded top layer of the agar plates. The plates containing the discs were allowed to stand for at least $30 \mathrm{~min}$ before incubated at $37^{\circ} \mathrm{C}$ for $24 \mathrm{~h}$. The diameter of the zone of inhibition produced by each antibiotic disc was 


\begin{tabular}{|c|c|c|}
\hline \multicolumn{3}{|c|}{$\begin{array}{l}\text { Table } 1 \text {. Percent of the DPPH radical } \\
\text { scavenging of the } T \text {. daenensis essential oil. }\end{array}$} \\
\hline \multicolumn{2}{|l|}{ Treatments } & $\begin{array}{l}\text { Percent of the DPPH } \\
\text { radical scavenging }\end{array}$ \\
\hline \multicolumn{2}{|l|}{ BHT } & $85.12 \pm 7.34 b^{* * *}$ \\
\hline \multirow{4}{*}{ T. daenensis } & $0.25 *$ & $55.28 \pm 5.01 \mathrm{~d}$ \\
\hline & 0.5 & $76.77 \pm 7.16 \mathrm{c}$ \\
\hline & 0.75 & $89.92 \pm 7.49 b$ \\
\hline & 1 & $96.27 \pm 8.60 \mathrm{a}$ \\
\hline
\end{tabular}

measured and interpreted using the CLSI zone diameter interpretative standards (CLSI, 2015). All data were presented as mean \pm standard deviation (SD). SPSS. Ver. 20 was used for statistical analysis. Comparison of means were studied using the one-way ANOVA and also post hoc turkey test. $P$ value $\leq 0.05$ was determined as significant level. All tests were done 3 times.

\section{RESULTS AND DISCUSSION}

We found that increase in the concentration of the $T$. daenensis essential oil caused increase in its antioxidant and also antibacterial effects $(P<0.05)$. Table 1 shows the antioxidant effect of $T$. daenensis essential oil against DPPH free radicals. We found that $T$. daenensis essential oil in a concentration of $1 \mathrm{mg} / \mathrm{ml}$ had the highest inhibitory effects on the DPPH free radicals $(96.27 \pm 8.60 \%)$. BHT synthetic antioxidant had the higher inhibitory effects on the DPPH free radicals than 0.25 and $0.5 \mathrm{mg} /$ $\mathrm{ml}$ concentration of $T$. daenensis essential oil.

Table 2 represents the antibacterial effects of the $T$. daenensis essential oil on several types of bacteria. The mean dimeter of the zone of inhibition for tested bacteria had a range of $6.03 \pm 0.28$ to $19.29 \pm 1.57$ millimeter. We found that the highest antibacterial effects were seen for the $1 \mathrm{mg} / \mathrm{ml}$ concentration of the $T$. daenensis essential oil on all tested bacteria and especially on $E$. coli $(19.29 \pm 1.57 \mathrm{~mm})$ and $K$. pneumonia $(18.0 \pm 1.69 \mathrm{~mm})$. Antibacterial effect of the T. daenensis essential oil was not considerable against $S$. aureus and B. cereus.

Table 3 represents the antibacterial effects of several types of antibiotic agents on tested bacteria. The mean dimeter of the zone of inhibition for tested bacteria had a range of $6.91 \pm 0.46$ to $14.41 \pm 1.38$ millimeter. We found that the highest diameter of the zone of inhibition of $S$. aureus, K. pneumonia, $P$. aeruginosa, L. monocytogenes, $E$. coli and $B$. cereus were seen for azithromycin $(15.28 \pm 1.22 \mathrm{~mm})$, ciprofloxacin $(12.27 \pm 1.15 \mathrm{~mm})$, ciprofloxacin $(14.41 \pm 1.38 \mathrm{~mm})$, azithromycin $(13.92 \pm 1.26$ $\mathrm{mm})$, ciprofloxacin $(10.71 \pm 0.74 \mathrm{~mm})$ and azithromycin $(11.79 \pm 1.06 \mathrm{~mm})$.We also found that the essential oil of the $T$. daenensis had a higher antibacterial effects on its high concentrations than several types of antibiotic agents.

The present investigation emerged the high antibacterial and antioxidant effects of the $T$. daenensis essential oil. Results of the present study showed that $T$. daenensis essential oil in concentrations of 0.75 and $1 \mathrm{mg} / \mathrm{ml} \mathrm{had}$ higher inhibitory effects on DPPH free radicals than BHT synthetic antioxidant. In addition, $T$. daenensis essential oil at mentioned concentration had a higher antibacterial effects on all tested bacteria than tetracycline, gentamicin and penicillin $\mathrm{G}$ antibiotic agents. High presence

\begin{tabular}{|c|c|c|c|c|}
\hline \multirow{2}{*}{ Bacteria } & \multicolumn{4}{|c|}{ Diameter of the zone of growth inhibition (mm) } \\
\hline & $0.25^{*}$ & 0.5 & 0.75 & 1 \\
\hline S. aureus & $7.33 \pm 0.58 C^{* * *} c^{* * * *}$ & $10.31 \pm 0.92 \mathrm{Cb}$ & $12.79 \pm 1.23 \mathrm{Ba}$ & $13.04 \pm 1.19 \mathrm{Ba}$ \\
\hline K. pneumoniae & $9.25 \pm 0.75 B d$ & $12.23 \pm 1.04 \mathrm{Bc}$ & $15.71 \pm 1.33 \mathrm{Ab}$ & $18.0 \pm 1.69 \mathrm{Aa}$ \\
\hline P. aeruginosa & $9.09 \pm 0.84 \mathrm{Bc}$ & $11.89 \pm 1.09 \mathrm{Bb}$ & $13.33 \pm 1.25 \mathrm{Bb}$ & $16.92 \pm 1.58 \mathrm{Ba}$ \\
\hline L. monocytogenes & $8.85 \pm 0.67 \mathrm{Bc}$ & $11.26 \pm 0.72 \mathrm{Bb}$ & $13.72 \pm 1.10 \mathrm{Bb}$ & $14.85 \pm 1.13 \mathrm{Ba}$ \\
\hline E. coli & $11.73 \pm 1.55 \mathrm{Ad}$ & $14.25 \pm 1.31 \mathrm{Ac}$ & $16.82 \pm 1.44 \mathrm{Ab}$ & $19.29 \pm 1.57 \mathrm{Aa}$ \\
\hline B. cereus & $6.03 \pm 0.28 \mathrm{Cc}$ & $8.94 \pm 0.75 \mathrm{Db}$ & $9.21 \pm 0.53 \mathrm{Cb}$ & $11.42 \pm 1.16 \mathrm{Ca}$ \\
\hline
\end{tabular}


Table 3. Antibacterial effects of the antibiotic agents on several types of bacteria.

\begin{tabular}{|l|l|l|l|l|l|}
\hline \multirow{2}{*}{ Bacteria } & \multicolumn{5}{|c|}{ Diameter of the zone of growth inhibition (mm) } \\
\cline { 2 - 6 } & Tetracycline & Azithromycin & Gentamicin & Penicillin G & Ciprofloxacin \\
\hline S. aureus & $5.21 \pm 0.42 \mathrm{C}^{*} \mathrm{~d}^{* *}$ & $13.28 \pm 1.22 \mathrm{Aa}$ & $6.37 \pm 0.54 \mathrm{Cd}$ & $12.88 \pm 1.07 \mathrm{Ab}$ & $9.15 \pm 0.39 \mathrm{Dc}$ \\
\hline K. pneumoniae & $7.38 \pm 0.67 \mathrm{Bc}$ & $12.13 \pm 1.15 \mathrm{Ca}$ & $9.64 \pm 0.71 \mathrm{Bb}$ & $10.13 \pm 1.07 \mathrm{Bb}$ & $12.27 \pm 1.15 \mathrm{Ba}$ \\
\hline P. aeruginosa & $7.52 \pm 0.65 \mathrm{Bc}$ & $11.33 \pm 1.05 \mathrm{Cb}$ & $12.27 \pm 1.21 \mathrm{Ab}$ & $13.14 \pm 1.26 \mathrm{Aa}$ & $14.41 \pm 1.38 \mathrm{Aa}$ \\
\hline L. monocytogenes & $7.20 \pm 0.62 \mathrm{Bc}$ & $13.92 \pm 1.26 \mathrm{Ba}$ & $7.14 \pm 0.45 \mathrm{Cc}$ & $11.85 \pm 1.08 \mathrm{Ab}$ & $10.52 \pm 0.84 \mathrm{Cb}$ \\
\hline E. coli & $8.31 \pm 0.65 \mathrm{Ab}$ & $10.71 \pm 1.00 \mathrm{Da}$ & $9.24 \pm 0.55 \mathrm{Bb}$ & $8.33 \pm 0.36 \mathrm{Cb}$ & $10.79 \pm 0.74 \mathrm{Ca}$ \\
\hline B. cereus & $7.25 \pm 0.31 \mathrm{Bc}$ & $11.79 \pm 1.06 \mathrm{Ca}$ & $6.91 \pm 0.46 \mathrm{Cc}$ & $10.21 \pm 1.05 \mathrm{Ba}$ & $8.22 \pm 0.67 \mathrm{Db}$ \\
\hline
\end{tabular}

"Dissimilar capital letters in each column shows significant differences less than 0.05

**Dissimilar small letters in each row shows significant differences less than 0.05 .

of antioxidant, flavonoid, phenol, carotenoid and volatile components are the main factor which cause high antioxidant effects of $T$. daenensis essential oil. In fact, essential oil of the $T$. daenensis is a source of 1,8-cineole, lanolool, $\alpha$-terpineol, geraniol, trans-thujan-4-ol, terpinen-4-ol, thymol and carvacrol which have potential antibacterial and antioxidant effects (Diaz-Maroto et al. 2006).

Several investigations focused on the antibacterial and antioxidant effects of $T$. daenensis essential oil (Sabahi et al. 2013; Damjanović-Vratnica et al. 2015; Amiri 2012).Sabahi et al. (2013) showed that the antioxidant potential of crude extract of $T$. daenensis by DPPH free radical scavenging (IC50 $=194 \pm 0.02 \mu \mathrm{g} / \mathrm{mL}$ ), nitric oxide scavenging $(74 \pm 0.0 \%)$ and hydroxyl radical scavenging ( $60.2 \pm 0.27 \%)$ was more active than its essential oil. In nitric oxide scavenging crude extract was more active than the antioxidant standard BHT, $42 \pm 0.79$. They showed that high presence of Geraniol (66.8\%), Geranyl acetate (13.9\%) and Beta caryophyllene (9.6\%) in the $T$. daenensis essential oil warrant its high antioxidant effects.

Damjanović-Vratnica et al. (2015) showed that geraniol (25.66\%), geranyl-acetate (20.34\%), linalool $(10.89 \%)$ and caryophyllene oxide (9.89\%) were the most commonly detected chemical components in the T. vulgaris essential oil. They showed that the essential oil of the T. vulgaris had considerable antimicrobial effects on $S$. aureus, E. coli, Candida albicansand K. pneumoniae. Amiri (2012) reported that antioxidant activity of polar subfraction of T. daenensis subsplancifolius (Celak) Jalas was found to be higher than other thymus species in
DPPH assay. He showed that the inhibitory effects of the T. daenensis subsplancifolius, T. daenensis subsplancifoliuspolar sub-fraction and T. daenensis subsplancifolius non-polar sub-fraction essential oils on DPPH free radical were $99.6 \pm 0.5,19.1 \pm 0.1$ and $248.7 \pm 1.6 \mu \mathrm{g} / \mathrm{ml}$, respectively. $T$. tosevii var. tosevii, $T$. tosevii var. degenii, T. tosevii var. longifrons, T. tosevii ssp. substriatus, $T$. longidens var. lanicaulis and $T$. caramanicus are other some Thymus species with high antioxidant and antibacterial effects (Vardar-Unlü et al. 2003; Ulukanli et al. 2011; Jia et al. 2010; Zarshenas and Krenn, et al. 2015).

Nikolić et al. (2013) revealed the high antimicrobial, antioxidant and antitumoractivity of $T$. serpyllum L., $T$. algeriensis Boiss. and Reut and T. vulgaris L. essential oils. They showed that Thymol was a major chemical component in all tested thymus species. Difference in the species of plant, method of sampling, part of plant used for essence extraction, method of extraction and geographical area caused difference in the chemical composition of thymus species and therefore variation in their antibacterial and antioxidant effects.

Bacterial strains of our investigation harbored the high levels of resistance against tetracycline, azithromycin, gentamicin, penicillin $\mathrm{G}$, and ciprofloxacin antibiotic agents. It may be due to the irregular and unauthorized prescription of these antibiotics in veterinary and also medical fields in Iran. High prevalence of resistance against these antibiotics have also been reported by other researchers (Momtaz et al. 2013; Dehkordi et al. 2014; Shahrani et al. 2014; Ranjbar et al. 2017) which showed an emerging demand to use from natural antibacterial agent's like T. daenensis. 


\section{CONCLUSION}

In conclusion, we identified a considerable inhibitory effects of the T. daenensis essential oil on DPPH free radicals and also high antibacterial effects of this plant against Gram-negative and Gram-positive bacteria. Results showed that $T$. daenensis essential oil in high concentrations had higher antibacterial and antioxidant effects. According to results, production of drug from the essential oil of the $T$. daenensis at 0.75 and $1 \mathrm{mg} /$ $\mathrm{ml}$ concentration is a good approach for treatment of the cases of E. coli, K. pneumonia, and P. aeruginosa bacteria. Judicious prescription of antibiotic according to the results of the disk diffusion method can eliminate the risk of occurrence of antibiotic resistance.

\section{ACKNOWLEDGEMENTS}

Author would like to thank the staff of the Food Science and Technology and also Medicinal Plants Research Centers of the Islamic Azad University of Shahrekord, Iran for their important technical help.

\section{REFERENCES}

Amiri, H. (2012): Essential Oils Composition and Antioxidant Properties of Three Thymus Species. Evid-Based Comp Alt Med. 2012, 1-8.

Clinical and Laboratory Standards Institute (CLSI). (2015): Performance Standards for Antimicrobial Susceptibility Testing; Twenty-Fifth Informational Supplement M100-S25. Wayne Pa.

Damjanović-Vratnica, B., Caković, D. andPerović, S. (2015): Composition and antimicrobial studies of essential oil of Thymus vulgaris from Montenegro. BiolNyssana. 6, 67-73.

Dehkordi, F. S., Yazdani, F., Mozafari, J. and Valizadeh, Y. (2014): Virulence factors, serogroups and antimicrobial resistance properties of Escherichia coli strains in fermented dairy products. BMC Res Notes. 7, 217.

Diaz-Maroto, M.S., Perez-Coello, S., Esteban, J. andSanz, J. (2006): Comparison of the volatile composition of wild fennel samples (Foeniculum vulgare Mill.) from Central Spain. J Agric Food Chem. 54, 6814-6818.

Huttner, A., Harbarth, S., Carlet, J., Cosgrove, S., Goossens, H., Holmes, A., Jarlier, V., Voss, A. and Pittet, D. (2013): Antimicrobial resistance: a global view from the 2013 World Healthcare-Associated Infections Forum. Antimicrob Resist Infect Control. 2, 31.
Jia, H. L., Ji, Q. L., Xing, S. L., Zhang, P. H., Zhu, G. L. and Wang, X. H.(2010): Chemical composition and antioxidant, antimicrobial activities of the essential oils of Thymus marschallianus Will. and Thymus proximus Serg. J Food Sci. 75, E59-65.

Kaye, K. S. and Pogue, J. M. (2015): Infections Caused by Resistant Gram-Negative Bacteria: Epidemiology and Management. Pharmacotherapy. 35, 949-62.

Momtaz, H., Dehkordi, F. S., Hosseini, M. J., Sarshar, M. and Heidari, M. (2013): Serogroups, virulence genes and antibiotic resistance in Shiga toxin-producing Escherichia coli isolated from diarrheic and non-diarrheic pediatric patients in Iran.Gut Pathog. 5, 39.

Nikolić, M., Glamoĉlija, J., Ferreira, I., Calhelha, R. C., Fernandes, A., Marković, T., Marković, D., Giweli, A. and Soković, M. (2014): Chemical composition, antimicrobial, antioxidant and antitumor activity of Thymus serpyllum L., Thymus algeriensis Boiss. and Reut and Thymus vulgaris L. essential oils. Industrial Crops Prod. 52,183-190.

Ranjbar, R., Masoudimanesh, M., Dehkordi, F. S., JonaidiJafari, N. and Rahimi, E. (2017): Shiga (Vero)-toxin producing Escherichia coli isolated from the hospital foods; virulence factors, o-serogroups and antimicrobial resistance properties. Antimicrob Resist Infect Control. 6, 4.

Ruhnke-Trautmann, M., Trautmann, M., Brückner, O., Weinke, T. and Wagner, J. (1989): Infection caused by gram-positive and gram-negative bacteria. A comparative study. Fortschr Med. 107, 477-80.

Shahrani, M., Dehkordi, F. S. and Momtaz, H. (2014): Characterization of Escherichia coli virulence genes, pathotypes and antibiotic resistance properties in diarrheic calves in Iran.Biol Res. 47, 28.

Ulukanli, Z., Cigremis, Y. and Ilcim, A. (2011): In vitro antimicrobial and antioxidant activity of acetone and methanol extracts from Thymus leucotrichius (Lamiaceae). Eur Rev Med Pharmacol Sci. 15, 649-57.

Vardar-Unlü, G., Candan, F., Sökmen, A., Daferera, D., Polissiou, M., Sökmen, M., Dönmez, E. and Tepe, B. (2003): Antimicrobial and antioxidant activity of the essential oil and methanol extracts of Thymus pectinatus Fisch. etMey. Var. pectinatus (Lamiaceae). J Agric Food Chem. 51, 63-7.

Woodford, N.and Livermore, D. M.(2009): Infections caused by Gram-positive bacteria: a review of the global challenge. J Infect. 59, S4-16.

Zarshenas, M. M.and Krenn, L.(2015): A critical overview on Thymus daenensis Celak.: phytochemical and pharmacological investigations. J Integr Med. 13, 91-8.

Zhang R, Eggleston K, Rotimi V, Zeckhauser RJ. Antibiotic resistance as a global threat: evidence from China, Kuwait and the United States. Global Health. 2, 6. 